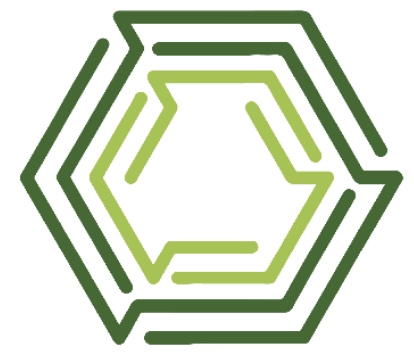

COINTER PDVAgro 2020

V CONGRESSO INTERNACIONAL DAS CIÊNCIAS AGRÁRIAS Edição 100\% virtual | 02 a 05 de dezembro ISSN:2526-7701 | PREFIXO DOI:10.31692/2526-7701

\title{
PÓS-COLHEITA DE ACEROLA E AVALIAÇÃO DE FRUTOS VOLTADOS AO MELHORAMENTO GENÉTICO DA ESPÉCIE: REVISÃO
}

\author{
POST COSECHA DE ACEROLA Y EVALUACIÓN DE FRUTAS CON EL \\ OBJETIVO DE MEJORA GENÉTICA DE LA ESPECIE: REVISIÓN
}

\section{POST HARVEST OF ACEROLA AND EVALUATION OF FRUITS AIMING AT GENETIC IMPROVEMENT OF THE SPECIES: REVIEW}

\author{
Apresentação: Comunicação Oral \\ Fernanda Tayla De Sousa Silva ${ }^{1}$; Andreia Rodrigues Da Silva ${ }^{2}$; Ana Thaís Campos De Oliveira ${ }^{3}$ Maria de \\ Fátima Costa Carneiro ${ }^{4}$; Ana Paula Ferreira de Almeida. ${ }^{5}$
}

\section{RESUMO}

DOI: $\underline{\text { https://doi.org/10.31692/2526-7701.VCOINTERPDVAgro.0466 }}$

O Brasil é considerado mundialmente um dos maiores produtores de acerola, devido suas condições climáticas, apresenta condições ideais para o cultivo desta fruta. Esse trabalho, por meio da revisão de literatura, teve o objetivo de identificar a produção científica que abordasse a temática de melhoramento genético e seleção de clone de aceroleira com propriedades superiores, destacando a relevância do tema. Os dados foram obtidos através da busca eletrônica nas bases de dados LILACS, PubMed, ScienceDirect, Periódicos da Capes e biblioteca eletrônica SciELO. Após a identificação dos artigos científicos, foram realizadas as seguintes etapas de seleção, a leitura criteriosa dos títulos, dos resumos e na íntegra. A amostra desta revisão consistiu em 9 estudos onde mostrava que predominantemente as técnicas mais usadas para identificar os melhores clones de aceroleira ou aqueles com características superiores ocorria por meio da análise de parâmetros dos frutos: diâmetro transversal, diâmetro lateral, textura, índice de formato do fruto, peso médio por fruto, peso da polpa, peso da semente, coloração da casca e índice de maturação. Assim como através da análise do potencial agronômico da planta: altura de planta (AP) diâmetro da copa (DC), crescimento total em 20 ramos e crescimento médio de ramos, produção de frutos. Os programas de melhoramento genéticos visam manter a qualidade dos frutos bem como uma produção uniforme, tendo em vista que esses padrões podem ser alcançados com o uso de clones com genes superiores. Foi possível observar a importância da realização de estudos de cruzamento de clones de aceroleira e avaliação dos seus parâmetros físico-químico e agronômico pois auxiliam na formação de novos pomares que produzam frutos que atendam às exigências das indústrias. Palavras-Chave: Acerola, Seletividade, Produção, Qualidade.

\footnotetext{
${ }^{1}$ Mestrado em Tecnologia de Alimentos, Instituto Federal de Educação, Ciência e Tecnologia do Ceará (IFCE), tayliinhaf@gmail.com.br

${ }^{2}$ Docente, Instituto Federal de Educação, Ciência e Tecnologia do Ceará (IFCE), andreia.rodrigues@ifce.edu.br

${ }^{3}$ Mestrado em Tecnologia de Alimentos, Instituto Federal de Educação, Ciência e Tecnologia do Ceará (IFCE) euthaiscampos.alimentos@gmail.com

4 Bacharelado em Nutrição, Instituto Federal de Educação, Ciência e Tecnologia do Ceará (IFCE), fati276@yahoo.com.br

${ }^{5}$ Mestrado em Tecnologia de Alimentos, Instituto Federal de Educação, Ciência e Tecnologia do Ceará (IFCE), ana.paula.ferreira.almeida123@gmail.com
} 


\begin{abstract}
Brazil is considered worldwide as one of the largest producers of acerola, due to its climatic conditions, it presents ideal conditions for the cultivation of this fruit. This work, through a literature review, aimed to identify scientific production that addressed the theme of genetic improvement and selection of aceroleira clone with superior properties, highlighting the relevance of the theme. The data were obtained through electronic search in LILACS, PubMed, ScienceDirect, Capes Periodicals and SciELO electronic library databases. After the identification of scientific articles, the following selection steps were carried out, with careful reading of titles, abstracts and in full. The sample of this review consisted of 9 studies which showed that predominantly the most used techniques to identify the best aceroleira clones or those with superior characteristics occurred through the analysis of fruit parameters: transversal diameter, lateral diameter, texture, shape index of the fruit, average weight per fruit, pulp weight, seed weight, skin color and ripeness index. As well as through the analysis of the agronomic potential of the plant: plant height (AP) crown diameter (DC), total growth in 20 branches and average growth of branches, fruit production. The genetic improvement programs aim to maintain the quality of the fruits as well as a uniform production, considering that these standards can be reached with the use of clones with superior genes. It was possible to observe the importance of carrying out crossbreeding studies of aceroleira clones and evaluating their physical-chemical and agronomic parameters as they help in the formation of new orchards that produce fruits that meet the requirements of the industries.

Keywords: Acerola, Selectivity, Production, Quality.
\end{abstract}

\title{
INTRODUÇÃO
}

A acerola cujo o nome científico Malpighia emarginata DC, também conhecida como cereja das Antilhas é um fruto avermelhado proveniente de um arbusto que mede em média dois a três metros de altura, possui folhas com pecíolos curtos de coloração verde-escura. $\mathrm{O}$ fruto apresenta uma estrutura drupa, carnosa e formato ovóide, variando quanto à forma, tamanho e peso. Estruturalmente a acerola é formada por três camadas: epicarpo camada mais externa e consiste em uma fina película de revestimento, o mesocarpo é a polpa e representa 70 a $80 \%$ do peso total e endocarpo é composto por três caroços unidos que dão ao fruto aspecto trilobado (PRODUTOR, 2004).

O Brasil é considerado mundialmente um dos maiores produtores de acerola, devido suas condições climáticas, apresenta condições ideais para o cultivo desta fruta. A maior parte da produção está centrada na região Nordeste do país, tendo como destaque os estados Ceará, Pernambuco, Paraíba e Bahia (RITZINGER; RITZINGER, 2011). A aceroleira é uma planta considerada resistente a seca e a temperatura elevada, mas possui pouca resistência aos ambientes frios, por essas características adaptou-se com facilidade as várias áreas tropicais, subtropicais e até semiáridas (FIGUEIREDO et al., 2014). É uma fruta apontada como uma excelente fonte de vitamina $\mathrm{C}$, com um teor mais elevado do que outras frutas como a laranja, caju, goiaba e o limão.

A maior parte da produção da acerola concentra-se no setor agroindustrial para a fabricação de polpa e sucos, por ser uma fruta extremamente perecível tem um alto percentual de perdas pós colheita e parte considerável da produção não é aproveitada (DE FREITAS, 
2014). A acerola é pouco consumida in natura, sendo comumente processada e comercializada predominantemente na forma de polpa congelada, mas destaca-se seu uso na fabricação de sucos, licores, confeitos, chicletes e ketchup (DE ASSIS COSTA; DE ANDRADE, 2003). A aceroleira é uma planta cuja suas variedades ainda se encontram indefinidas levando a desuniformidade nas características quantitativas e qualitativas dos frutos o que pode levar ao comprometimento da sua produção e comercialização (RITZINGER; RITZINGER, 2011).

O interesse do consumidor por alimentos naturais vem aumentando ao longo do tempo, pois cada vez mais as pessoas estão buscando uma alimentação nutricionalmente saudável e equilibrada que influencie diretamente na manutenção da sua saúde, com isso, nota-se um crescente aumento da procura por frutas e seus derivados. A acerola é considerada uma fruta funcional por possui na sua composição compostos bioativos capazes de conferir benefícios adicionais à saúde do consumidor, como: ácido ascórbico, antocianinas destacando o fruto no campo de alimentos funcionais, pela capacidade desses compostos capturar radicais livres no corpo humano (KAHL et al., 2011).

A acerola pode ser propagada de forma sexuada por meio da semente ou de forma assexuada ou vegetativa, através da estaquia e enxertia. A forma sexuada é a opção mais empregada no Brasil, por ser uma opção fácil e econômica, mas apresenta como desvantagem a não uniformidade das características da planta dos seus frutos. Já a propagação estaquia proporciona melhora na produção além de assegurar pomares com plantas uniformes (BORDIN et al., 2005).

Diante do exposto o presente estudo teve o propósito de buscar na literatura estudos que abordassem a temática de melhoramento genético e seleção de clone de aceroleira com características superiores.

\section{FUNDAMENTAÇÃO TEÓRICA}

O melhoramento genético de plantas contribui na ampliação das exportações e redução da importação de alimentos. Entre as diversas contrubuições destacam-se a melhoria na qualidade do alimento, aumento da produtividade e resistência a doenças e a pragas. Tal método basea-se na coleta de grão de plantas, presumivelmente com características superiores as demais, e seu uso para a produção de novas espécies de plantas com características semelhantes ás que deram origem (AMABILE et al., 2018; NICOLI et al., 2017).

A aceroleira é pertencente a classe Angiospermae, da família Malpighiaceae, gênero Malpighia e espécie Malpighia emarginata DC. É uma árvore de pequeno a médio porte que dispoe de tronco único, com ramificações por vários ramos lenhosos, curvados frequentemente 


\section{PÓS-COLHEITA DE ACEROLA E AVALIAÇÃO DE FRUTOS}

para baixo, possui copas diversificadas em razão da grande variabilidade genética. Além disso, essas plantas possuem sistema radicular pivotante, em solos profundos e férteis suas raízes podem alcançar até $1 \mathrm{~m}$ de profundidade (DINIZ, 2020).

A planta de acerola necessita de luz pois é sob influência desta que ocorre a produção de vitamina $\mathrm{C}$, através da fotossíntese. Desse modo, a radiação solar interfere diretamente na qualidade dos frutos, tendo em vista que o ácido ascórbico é um antioxidante que influencia os processos bioquímicos, protegendo o sistema fotossintético dos danos solares (DINIZ, 2020).

O fruto é climatérico e passa por várias etapas de alterações durante o seu ciclo: maturação, amadurecimento e senescência, ocorrendo degradação da clorofila, aparecimento dos carotenóides, diminuição da acidez e perda acentuada de vitamina $\mathrm{C}$, durante essas etapas. Por ser uma fruta climatérica se deteriora facilmente. Levando isso em consideração, a seleção de clones com maior atividade antioxidante é uma alternativa para obtenção de frutos que possam ser armazenados por um maior período de tempo (SILVA et al., 2010).

A importância do cultivo da acerola está atribuída também as propriedades nutricionais do fruto, por ser uma fruta rica em vitamina $\mathrm{C}$ e outros componentes antioxidantes. Sendo que a quantidade de vitamina $\mathrm{C}$ e carotenóides, compostos precursores da vitamina $\mathrm{A}$ e licopeno, compostos fenólicos e flavonoides irão variar de acordo com a forma de cultivo, as condições climáticas e estágio de maturação do fruto (KAHL et al., 2011).

O tecido vegetal tem capacidade antioxidante pois é capaz de retardar ou impedir danos nos tecidos causados pela oxidação. A habilidade de neutralizar os radicais livres se dá por meio da atividade de enzimas e dos compostos antioxidantes não enzimáticos como a vitamina $\mathrm{C}$, carotenóides, tocoferóis e os compostos fenólicos (SILVA et al., 2010).

A necessidade de encontrar novas variedades genéticas com boas características agronômicas tem despertado o interesse de pesquisadores e participante de programas de melhoramento genético (RITZINGER; RITZINGER, 2011). Portanto, para a propagação de clones é importante o uso de uma grande variabilidade genética de aceroleira que seja propagada via vegetativa, que tenham o maior número de características agronômicas desejáveis (BORDIN et al., 2005).

\section{METODOLOGIA}

O presente estudo trata-se de uma revisão da literatura de natureza qualitativa, é uma investigação que utiliza métodos rígidos afim de sintetizar informações de outros estudos, gerando um conhecimento mais aprofundado sobre um tema investigado (GALVÃO; PEREIRA, 2014). Buscou-se analisar publicações científicas que abordassem a seguinte 
temática: pós colheita de acerola visando avaliação dos frutos e o melhoramento genético da espécie. A pesquisa foi dividida em três fases: planejamento onde foi realizado o delineamento do estudo, execução e discussão dos resultados. Todos os passos apresentados seguiram alguns critérios metodológicos. Figura 01.

Figura 01: Fases de elaboração da pesquisa

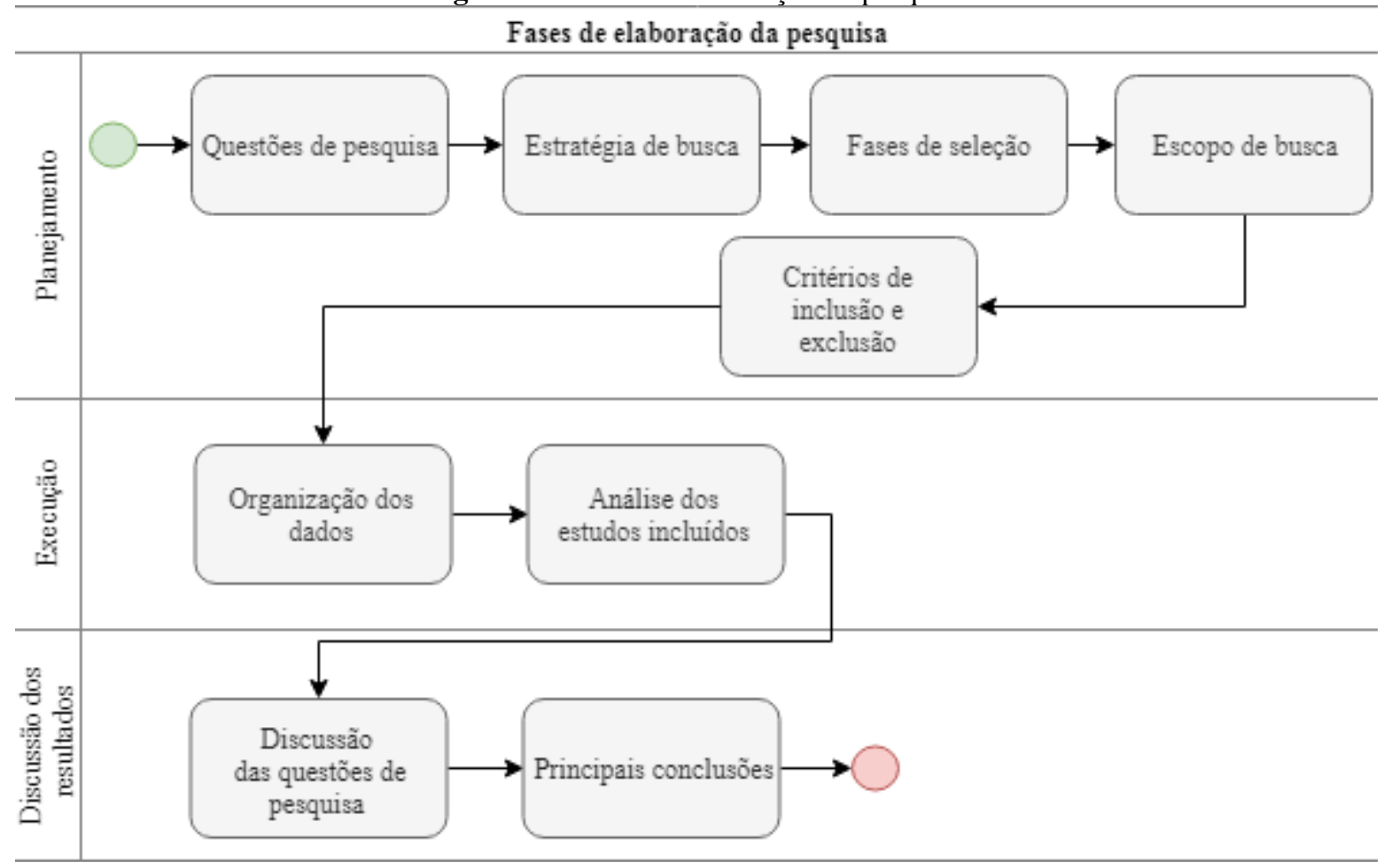

Fonte: Própria (2019).

\section{Planejamento do estudo}

Para coleta de dados foram elaboradas cinco questões de pesquisa (QP) relacionadas aos objetivos desta revisão, possibilitando assim, coletar e sistematizar informações pertinentes dos trabalhos encontrados na literatura.

QP1 - Qual abordagem ou métodos foram utilizados? O intuito desta questão foi identificar quais foram os métodos ou abordagens utilizadas para identificar os melhores clones de aceroleira.

QP2 - Quais parâmetros nos frutos eram avaliados. Com esta questão buscou-se analisar, quais eram os parâmetros de qualidade avaliados nos frutos pós-colheita.

QP3 - Quais parâmetros da planta eram avaliados? O propósito desta questão foi analisar os principais parâmetros da planta que eram avaliados e constatar sua produtividade e possível potencial agrônomo. 


\section{PÓS-COLHEITA DE ACEROLA E AVALIAÇÃO DE FRUTOS}

QP4 - Quais os clones, genótipos ou pomares presentes nos estudos? Esta questão teve por finalidade identificar os principais clones, genótipos e pomares apresentados nos estudos para se ter clareza das condições em que as plantas eram cultivadas.

QP5 - Quais os melhores genótipos ou clones identificados nos estudos? Desta forma com esta questão buscou-se apresentar os melhores clones que poderiam ser lançados no mercado comercial.

\section{Estratégia de busca}

A estratégia de busca é uma etapa determinante para assegurar a validade das informações apresentadas e que os estudos relevantes ao tema estudado serão incluídos no trabalho, com isso foi realizado a combinação dos descritores e seus respectivos sinônimos referentes a temática abordada nesta revisão. As combinações dos descritores são usadas para realizar buscas nas bases eletrônicas ou bibliotecas digitais. Assim, foi adotado a seguinte estratégia de busca: identificou-se os principais termos representativo ao tema; realizou-se a tradução dos termos para o idioma inglês; utilizou-se o operador booleano OR para ligar termos sinônimos; utilizou-se o operador AND para ligar os termos chaves.

Para a coleta dos estudos utilizou-se nas bibliotecas eletrônicas a combinação dos de descritores na língua inglesa com seus respectivos sinônimos e conectados por operadores booleanos formando a seguinte chave de busca: ("malpighia emarginata" OR "Acerola") AND ("postharvest" OR "selection" OR "production") AND ("plant breeding" OR "genetic improvement" OR "quality").

A seleção dos trabalhos decorreu em 3 fases, a primeira fase foi a escolha das bases de dados eletrônicas para ser a fonte de busca, ou seja, execução da pesquisa, onde foram executadas as expressões de busca em cada uma dessas bases. Os estudos retornados na busca, foram agrupados e formaram um conjunto de publicações que passaram por um processo de análise. Na segunda fase, as publicações duplicadas e trabalhos não científicos foram descartados. Além disso, ocorreu aplicação dos primeiros filtros de seleção dos trabalhos, através da leitura criteriosa dos títulos e abstracts os estudos foram incluídos ou excluídos nesta revisão. Já na terceira fase foi feito o download do texto completo e os trabalhos lidos na sua totalidade. Foram aplicados os critérios de inclusão e exclusão, por fim teve a aplicação das questões de pesquisa e as respostas foram registradas e analisadas.

A busca foi definida a partir da determinação de alguns parâmetros de seleção: período de tempo, idioma e origem. Buscou-se não limitar muito o período de publicação para tornar a pesquisa mais abrangente possível do tema proposto. Em relação ao idioma optou-se por 
selecionar publicações nos idiomas inglês e português. Quanto a origem dos artigos se deu pela busca realizada em bases de dados eletrônicas por meio dos mecanismos de busca. As bibliotecas selecionadas deveriam atender aos seguintes critérios: possuir mecanismos que permitisse uso de expressões busca; Permitir a leitura das publicações na íntegra; Incluir em sua base publicações na área de tecnologia em alimentos e pós colheita.

Com isso as bibliotecas eletrônicas selecionadas foram as seguintes: Scientific Eletronic Library Online (SciELO), Periódicos da Capes, Literatura Latino-Americana e do Caribe em Ciências da Saúde (LILACS), PubMed e ScienceDirect. Na base de dados Periódicos da Capes foi usado os filtros próprios das bases afim de refinar os resultados encontrado: data de publicação 2014 a 2019, filtro artigo, e idioma Português e Inglês. Na base eletrônica Pubmed utilizou-se somente filtro do período de publicação 2014 a 2019.

\section{Critérios de inclusão e exclusão}

A investigação seguiu algumas etapas de seleção, onde foram atribuídos alguns critérios de inclusão e exclusão. Foram selecionados os trabalhos que atendiam a seguinte temática "Estudos que descrevessem abordagem de melhoramento genético e seleção de clone de aceroleira superiores".

Quanto aos critérios de elegibilidade: estudos que abordavam o tema em questão, no idioma português e inglês cujo seu texto estivesse disponível na íntegra de forma gratuita. Como critérios de exclusão atribuídos: trabalhos que não abordavam a temática proposta, estudos cujo as abordagens não tinham relação com pós colheita de acerola e seleção de clones, publicações no formato de monografias, dissertações e teses.

\section{Coleta de dados}

Foi feito um levantamento de dados através da busca eletrônica, durante o período de março a abril de 2019, nas respectivas bases de dados, SciELO (Scientific Eletronic Library Online), Periódicos da Capes, LILACS (Literatura Latino-Americana e do Caribe em Ciências da Saúde), PubMed e ScienceDirect. Ao todo foram encontrados 256 trabalhos, excluíram-se 247 a partir da leitura dos títulos e resumos, além da aplicação dos critérios de inclusão e exclusão. Para organização dos trabalhos foi utilizado o serviço de planilha eletrônica disponibilizada pelo Google, uma ferramenta prática e gratuita. A Figura 2 apresenta as etapas de seleção dos artigos. 
Figura 02: Fluxograma das etapas de seleção

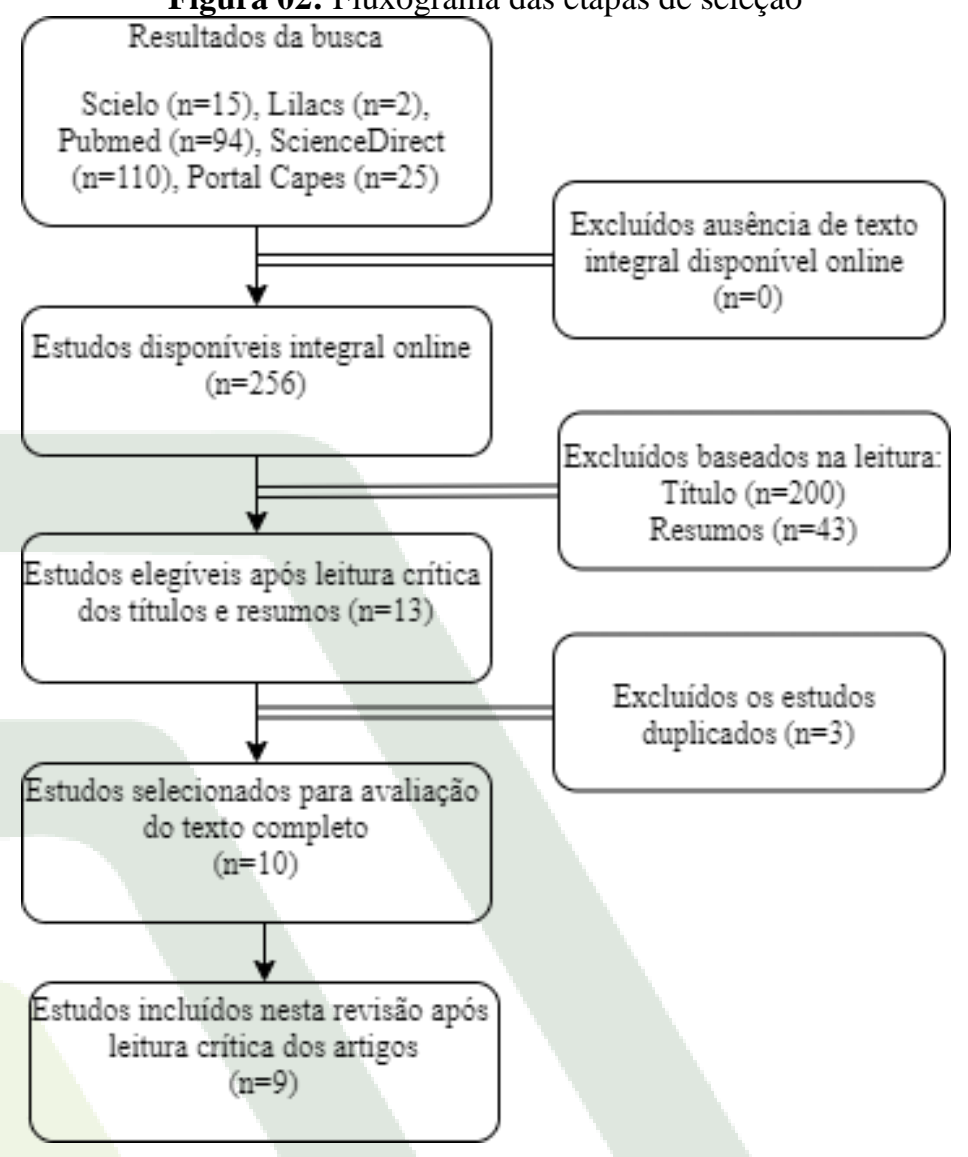

Fonte: Própria (2019).

\section{RESULTADOS E DISCUSSÃO}

Foram encontrados 256 artigos, mas somente 9 estudos atenderam aos critérios de seleção e foram incluídos nesta revisão. Dos 9 artigos selecionados, 7 apresentavam-se na língua portuguesa e 2 na língua inglesa. O Quadro 1 expõe os trabalhos incluídos apresentando quanto a sua identificação, referência, título do artigo e origem de busca.

Quadro 01: Publicações selecionadas para esta revisão

\begin{tabular}{|llll|}
\hline ID & Referência & \multicolumn{1}{c|}{ Título } & Origem \\
\hline E1 & Paiva et al., 1999 & $\begin{array}{l}\text { Parâmetros genéticos em progênies de polinização livre de } \\
\text { acerola. }\end{array}$ & Scielo \\
\hline E2 & $\begin{array}{c}\text { Carpentieri-pipolo et } \\
\text { al., 2000 }\end{array}$ & $\begin{array}{l}\text { Seleção de genótipos parentais de acerola com base na } \\
\text { divergência genética multivariada }\end{array}$ & Scielo \\
\hline E3 & Gomes et al., 2000 & Variabilidade fenotípica em genótipos de acerola & Scielo \\
\hline E4 & Brunini et al., 2004 & $\begin{array}{l}\text { Caracterização física e química de acerolas provenientes de } \\
\text { diferentes regiões de cultivo }\end{array}$ & Scielo \\
\hline
\end{tabular}




\begin{tabular}{|llll|}
\hline E5 & Musser et al., 2005 & $\begin{array}{l}\text { Caracterização física e de produção de acerola do banco ativo } \\
\text { de germoplasma em Pernambuco }\end{array}$ & Scielo \\
\hline E6 & Lima et al., 2007 & $\begin{array}{l}\text { Variação sazonal da concentração de macronutrientes em } \\
\text { folhas de diferentes genótipos de aceroleira }\end{array}$ & Scielo \\
\hline E7 & Neto et al., 2012 & $\begin{array}{l}\text { Caracterização agronômica e potencial antioxidante de frutos } \\
\text { de clones de aceroleira }\end{array}$ & Scielo \\
\hline E8 & Souza et a.1, 2014 & $\begin{array}{l}\text { Antioxidant compounds and total antioxidant activity in fruits } \\
\text { of acerola from cv. Flor Branca, Florida sweet and BRS 366/ }\end{array}$ & Capes \\
\hline E9 & Souza et al., 2017 & $\begin{array}{l}\text { Quality of acerola (Malpighia emarginata) treated with } \\
\text { gibberelic acid and stored under refrigeration }\end{array}$ & Scielo \\
\hline
\end{tabular}

Fonte: Própria (2019).

Os artigos científicos incluídos nesta revisão foram respectivamente organizados e descritos no Quadro 02 a seguir conforme autor/ano, objetivos, amostra, metodologia e solução proposta. 


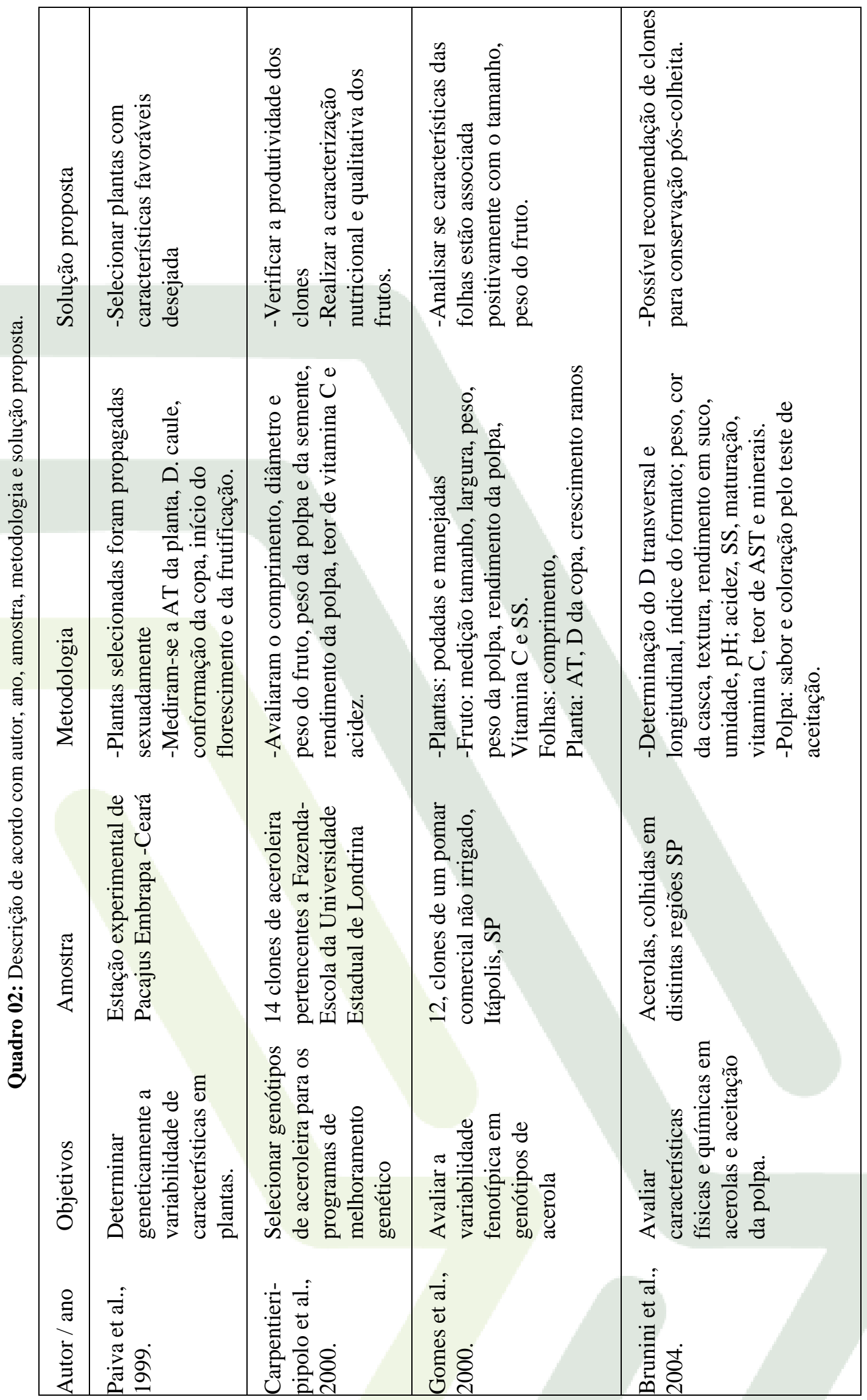




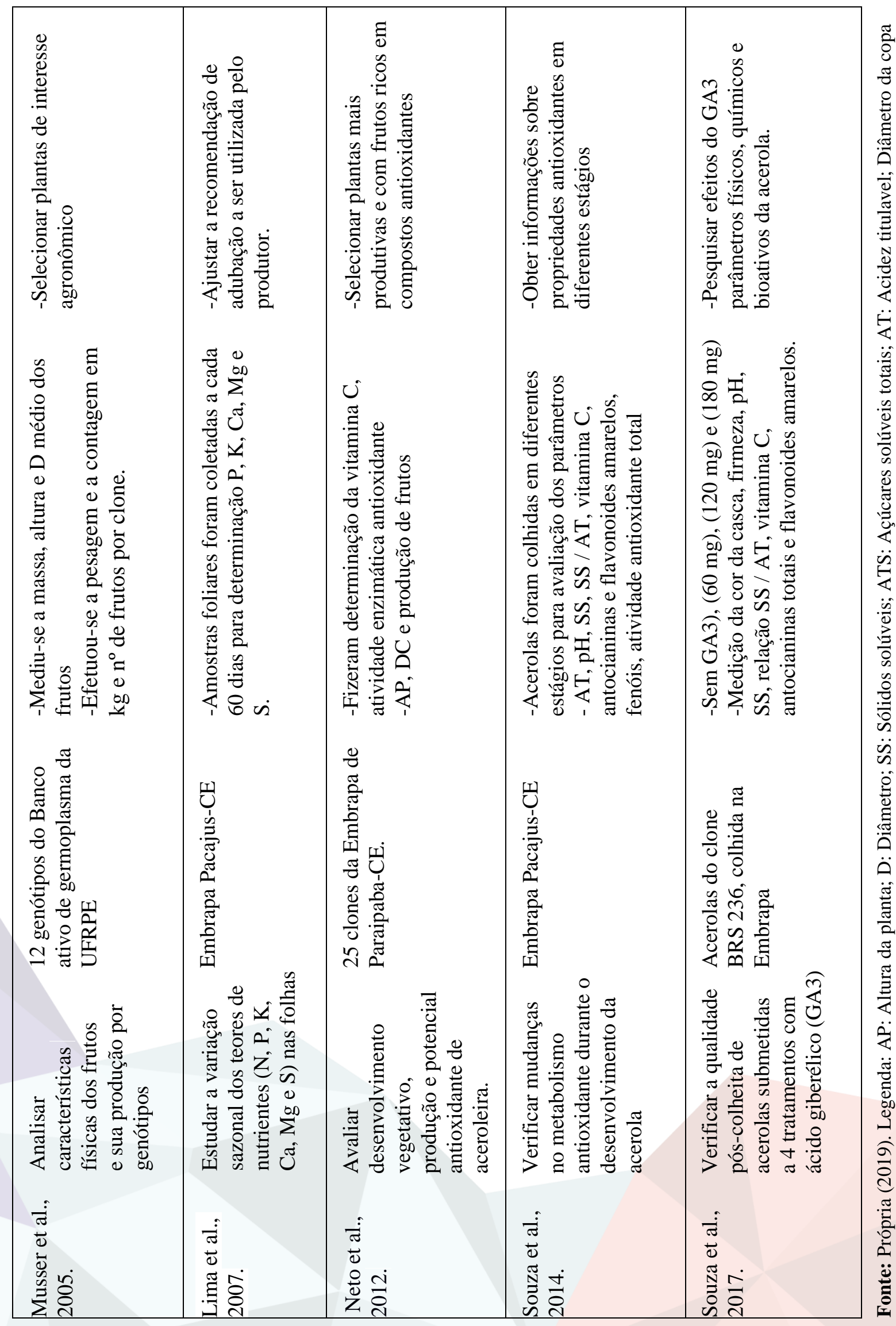




\section{PÓS-COLHEITA DE ACEROLA E AVALIAÇÃO DE FRUTOS}

Segundo Brunini et al. (2004) ainda não foram totalmente identificados clones de acerola com características bem definidas, por isso em um mesmo pomar pode-se ter plantas com crescimento divergente e frutos com tamanho, sabor e cores diferenciados, fatores esses que tem impulsionado instituições a aperfeiçoarem pesquisas voltadas a seleção de plantas e caracterização dos seus frutos, principalmente para selecionar acerolas com alto teor de vitamina C. Por tanto as questões de pesquisas foram primordiais para coletar os dados pertinentes dos trabalhos o que possibilitou discutir as informações relevantes dos estudos incluídos.

A classificação dos estudos segundo as abordagens para identificação de clones com características superiores foi agrupada e o Quadro 3 apresentada essas respectivas abordagens.

Quadro 03: Classificação das abordagens empregadas

\begin{tabular}{|ccc|}
\hline Categoria & Publicações & ID das publicações \\
\hline Propagação sexuada & 1 & E1 \\
Recomendação de cruzamentos & 1 & E2 \\
Teste com banco de genótipos & 1 & E5 \\
Caracterização físico-química da fruta & 7 & E2, E3, E4, E5, E7, E8, E9 \\
Análise das plantas & 4 & E1,E5, E6, E7 \\
\hline
\end{tabular}

Fonte: Própria (2019).

As principais técnicas usadas para avaliar quais eram os melhores clones de aceroleira ou aqueles com características superiores era por meio da análise de parâmetros dos frutos e do potencial agronômico da planta. Por tanto, as abordagens predominantes utilizadas pelos estudos foram; 1 estudo fez propagação de plantas de modo assexuado, 1 estudo buscou identificar genótipos e recomendações de cruzamentos de clones e 1 estudo realizou teste com o banco de genótipos, ou seja, os clones foram cultivados e tiveram seus frutos colhidos para posterior análises.

Quanto às abordagens empregadas, observa-se como mostra no Quadro 3 que 7 estudos realizaram caracterização físico-química dos frutos da aceroleira e 4 trabalhos propuseram analisar os parâmetros da planta, assim como medição da sua produtividade. Além disso 1 trabalho também estudou a aceitação da polpa do fruto. Foi apresentado 1 trabalho cujo o intuito foi caracterizar as folhas da aceroleira e analisar a variação sazonal dos teores de minerais no tecido foliar. No estudo Musser et al. (2005) ressaltam que os programas de melhoramento 
genético conduzem suas pesquisas a partir da avaliação de características agronômicas da planta e parâmetros físico-químicos e qualitativos dos frutos.

As análises das medidas feitas no fruto da aceroleira correspondendo a sua casca, medidas realizadas na polpa e na semente, estão dispostas no Quadro 4. Do mesmo modo também são apresentados os principais parâmetros físico-químicos analisados.

Quadro 4: Parâmetros avaliados nos frutos

\begin{tabular}{|c|c|c|}
\hline Variáveis & Publicações & ID das publicações \\
\hline \multicolumn{3}{|l|}{ Físicas } \\
\hline Medidas no fruto & 5 & E2, E3, E4, E5 e E9 \\
\hline Medidas na polpa & 3 & $\mathrm{E} 2, \mathrm{E} 3, \mathrm{E} 4$ \\
\hline Semente & 1 & $\mathrm{E} 2$, \\
\hline \multicolumn{3}{|l|}{ Físico-químicas } \\
\hline Vit. C, AT e SS & 5 & E2, E3, E4, E8 e E9 \\
\hline $\mathrm{pH}$ & 3 & E4, E8 e E9 \\
\hline Atividade antioxidante & 3 & E7, E8 e E9 \\
\hline
\end{tabular}

Fonte: Própria (2019). Vit: Vitamina; AT: Acidez titulavel; SS: Solidos soluveis totais

Dos 9 estudos selecionados, 5 trabalhos fizeram análises físicas dos frutos, cujos as principais variáveis estudadas foram a medição do diâmetro transversal, diâmetro lateral, textura, índice de formato do fruto, peso médio por fruto, peso da polpa, peso da semente, coloração da casca e índice de maturação. A cor dos frutos é um parâmetro que interfere na sua escolha considerado uma das características mais atrativas e determinante da preferência dos consumidores (BRUNINI et al., 2004).

Segundo Carpentieri-pipolo et al. (2000) frutos grandes que possuem um maior diâmetro geralmente são os que apresentam uma maior quantidade de polpa sendo esse um fator favorável a seleção. No estudo Souza et al. (2017) destacaram características importantes consideradas determinantes na qualidade pós colheita das acerolas, como a cor que está diretamente associado a concentração de pigmentos que na acerola tem predominância as antocianinas. Outro parâmetro físico importante é a firmeza, que está relacionado com estrutura das paredes celulares e sua integridade, ressaltando que frutos com alta firmeza possui uma vida útil pós colheita mais prolongada.

Do mesmo modo, dentre os estudos avaliados 7 realizaram a caracterização físicoquímica da acerola dos quais os parâmetros analisados eram os seguintes: determinação do teor 


\section{PÓS-COLHEITA DE ACEROLA E AVALIAÇÃO DE FRUTOS}

umidade, pH, acidez titulável (AT), teor de sólidos solúveis (SS), teor de açúcares solúveis totais, vitamina C, antocianinas e flavonóides amarelos, fenóis, atividade antioxidante total e determinação de alguns minerais (P, K, Ca, Mg, S, Fe, Zn, Cu, Mn).

No estudo Gomes et al. (2000) destacam que a síntese da vitamina C está diretamente associada a presença de luminosidade, onde frutos expostos ao sol retém elevada quantidade dessa vitamina, além disso uma maior disponibilidade de água também auxilia em uma maior produção de ácido ascórbico pela planta, mas o excesso hídrico resulta em frutos com menos teor de açúcares e vitamina C. A caracterização nutricional e a qualidade dos frutos correlacionam-se com os teores de vitamina $\mathrm{C}$ acima de $1.000 \mathrm{mg} / 100 \mathrm{~g}$ de polpa se valor que enquadra-se aos critérios impostos pela indústria de alimentos mas o nível mínimo exigido para comercialização internacional compreende $1.200 \mathrm{mg} / 100 \mathrm{~g}$ de polpa (Carpentieri-pipolo et al., 2000).

Quanto aos parâmetros da planta aceroleira considerados nos estudos foram agrupados e estão apresentados no Quadro 5 a seguir.

Quadro 05: Parâmetros avaliados nos frutos

\begin{tabular}{|lcc|}
\hline \multicolumn{1}{|c|}{ Variáveis } & Publicações & ID das publicações \\
\hline Planta, AP e DC & 3 & E1, E2 e E7 \\
Folha & 2 & E3 e E6 \\
Produção de frutos & 2 & E1, E5 e E7 \\
\hline
\end{tabular}

Fonte: Própria (2019). AP: Altura da planta; DC: Diâmetro da copa

Quanto as análises feitas nas plantas de aceroleira, 5 estudos efetuaram essa abordagem, 3 tiveram a intenção de verificar a média da produção dos frutos por clones, ou seja, verificar a produtividade desses genótipos. Destaca-se os principais parâmetros analisados; medição da altura de planta (AP) diâmetro da copa (DC), crescimento total em 20 ramos e crescimento médio de ramos, produção de frutos. As folhas das aceroleiras eram analisadas quanto ao seu comprimento e largura. Além disso 1 estudo analisou dos teores de $\mathrm{N}, \mathrm{P}, \mathrm{K}, \mathrm{Ca}, \mathrm{Mg}$ e $\mathrm{S}$ no tecido foliar.

A fim de obter uma elevada produção de acerola, e frutos com maior qualidade é imprescindível que as necessidades nutricionais das plantas sejam alcançadas. No estudo. Lima et al. (2007) destacam que a importância de conhecer a época mais apropriada para realizar a adubação com o intuito de atender as necessidades das plantas e obter frutos com qualidades superiores. 
Nos trabalhos incluídos os clones ou genótipos de aceroleira estudados foram bastante diversificados, significando que existe uma grande variedade de clones a serem explorados para conhecer suas variáveis agronômicas e nutricionais benéficas e assim possivelmente realizar uma recomendação para criação de novos plantios. Dentre as características de plantas usadas para selecionar clones em plantações comerciais, destaca-se o porte, a conformação da copa e a produtividade da planta, assim como parâmetros do fruto, seu tamanho, sabor, coloração e rendimento da polpa (PAIVA et al., 1999).

Os melhores clones, considerados pelos trabalhos avaliados, eram aqueles possuíam características agronômicas e físico-químicas favoráveis. No estudo Musser et al. (2005) consideraram que os melhores clones foram os mais produtivos e que apresentaram medidas como massa e diâmetro do fruto que atenderam as exigências das indústrias. Já no Neto et al. (2012) os clones recomendados foram as plantas que apresentavam um pequeno porte fator que facilita o processo de colheita dos frutos, além de plantas com maior diâmetro de copa e frutos com alta atividade enzimática e antioxidante. No Brunini et al. (2004) indicaram como melhores os que obtinham frutos com o maior teor de ácido ascórbico.

Com isso os programas de melhoramento genético preocupam-se em selecionar genótipos parenterais com boas características genéticas para realizar a hibridação desses clones e gerar plantas que reúnam o maior número de caracteres favoráveis (CARPENTIERI-PIPOLO et al., 2000). O estudo Paiva et al. (1999) cita características primordiais para formação de novos pomares que são plantas com boa formação de copa, tolerante as doenças e pragas, frutos com maior peso, tamanho e cor vermelho-purpura além de alto teor de vitamina $\mathrm{C}$ e sólidos solúveis.

\section{CONCLUSÕES}

Os estudos mostraram que os programas de melhoramento genéticos visam aumentar a qualidade dos frutos e sua produção. Além disso estão buscando cada vez mais a produção de frutos uniforme, com elevado conteúdo de vitamina $\mathrm{C}$ e compostos antioxidantes que favorecem o prolongamento da vida pós colheita do fruto. Sendo que esses padrões podem ser alcançados com o uso de clones parenterais que possuem genes superiores.

Diante disso, vê-se a importância de realizar mais estudos de cruzamento de clones de aceroleira e avaliar seus parâmetros físico-químicos e agronômicos para auxiliar na formação de novos pomares que atendam às exigências das indústrias e produzam frutos para importação e exportação comercial. 


\section{REFERÊNCIAS}

AMABILE, R. F.; VILELA, M. S.; PEIXOTO, J. R. Melhoramento de plantas: variabilidade genética, ferramentas e mercado. Embrapa Cerrados-Livro técnico (INFOTECA-E), 2018.

BORDIN, I. et al. Desenvolvimento de mudas de aceroleira propagadas por estacas e sementes em solo compactado. Ciência Rural, v. 35, n. 3, p. 530-536, 2005.

BRUNINI, M. A. et al. Caracterização física e química de acerolas provenientes de diferentes regiões de cultivo. Rev. Bras. Frutic, p. 486-489, 2004.

CARPENTIERI-PÍPOLO, V. et al. Seleção de genótipos parentais de acerola com base na divergência genética multivariada. Pesquisa Agropecuária Brasileira, v. 35, n. 8, p. 1613$1619,2000$.

CUNHA NETO, J. et al. Caracterização agronômica e potencial antioxidante de frutos de clones de aceroleira. Revista Ciência Agronômica, v. 43, n. 4, p. 713-721, 2012.

DE ASSIS COSTA, F.; DE ANDRADE, W. D. C. A Cultura da Acerola no Brasil e no Pará: Aspectos estruturais de produção e mercado. Francisco de Assis Costa, 2003.

DE FREITAS, Claisa Andréa Silva et al. Acerola: produção, composição, aspectos nutricionais e produtos. Current Agricultural Science and Technology, v. 12, n. 4, 2014.

DINIZ, J. V. Sistemas de colheita na cultura da acerola: estudo operacional (malpighia emarginata. DC). Fortaleza, 2020. 16 p. Dissertação (Engenharia de Sistemas Agrícolas). Universidade Federal do Ceará, UFC, 2020.

EVERALDO, GOMES JOSÉ et al. Variabilidade fenotípica em genótipos de acerola. Pesquisa Agropecuária Brasileira, 2000.

FIGUEIREDO NETO, A. et al. Determinação de vitamina ce avaliação físico-química em três variedades de acerola cultivadas em Petrolina-PE. Nucleus, v. 11, n. 1, p. 83-92, 2014.

GALVÃO, T. F.; PEREIRA, M. G. Revisões sistemáticas da literatura: passos para sua elaboração. Epidemiologia e Serviços de Saúde, v. 23, p. 183-184, 2014.

KAHL, V. F. S. et al. Análise dos potenciais antigenotóxico e antioxidante de duas variedades de acerola (Malpighia glabra L.), Fp-19 e Okinawa, em diferentes estágios de maturação. Revista de iniciação Científica da UIBRa, v. 1, n. 9, 2011.

LIMA, R. de L. S. de et al. Variação sazonal da concentração de macronutrientes em folhas de diferentes genótipos de aceroleira. Revista Brasileira de Fruticultura, p. 652-656, 2007.

MUSSER, R. dos S. et al. Caracterização física e de produção de acerola do banco ativo de germoplasma em Pernambuco. Revista Brasileira de Fruticultura, v. 27, n. 2, p. 320-323, 2005 .

NICOLI, C.F. et al. Agronomia colhendo as safras do conhecimento. Alegre - ES, 2017.

PAIVA, João Rodrigues de et al. Parâmetros genéticos em progênies de polinização livre de 
acerola. Pesquisa Agropecuária Brasileira, v. 34, n. 4, p. 629-634, 1999.

PRODUTOR, D. A. Instituto Centro de Ensino Tecnologico. Fortaleza: Edições Demócrito Rocha, 2004.

RITZINGER, R.; RITZINGER, C. H. S. P. Acerola. Embrapa Mandioca e FruticulturaArtigo em periódico indexado (ALICE), 2011.

SILVA, M. L. C. et al. Compostos fenólicos, carotenóides e atividade antioxidante em produtos vegetais. Semina: Ciências Agrárias, v. 31, n. 3, p. 669-681, 2010.

SOUZA, K. O. DE et al. Quality of acerola (Malpighia emarginata) treated with gibberelic acid and stored under refrigeration. Revista Brasileira de Fruticultura, v. 39, n. 4, 2017.

SOUZA, Kellina Oliveira de et al. Antioxidant compoundsand total antioxidant activity in fruits of acerola from cv. Flor Branca, Florida Sweet and BRS 366. Revista Brasileira de Fruticultura, v. 36, n. 2, p. 294-304, 2014. 